\title{
MUST APPENDICITIS BE STILL CONSIDERED AS A RARE COMPLICATION IN PARAPLEGIA?
}

\author{
By P. Dollfus, M.D., G. L. Holderbach, M.D., J. M. Husser, M.D. \\ and D. JACOB-ChIA, M.D. \\ Mulhouse, France
}

ONE can be surprised by the few cases of appendicitis diagnosed and operated, as well as the cases of peritonitis of appendicitis origin giving an acute surgical abdomen, which have been published in the literature on paraplegia (Greenfield, I949; Bors, I966; Comarr, I966). It is more than probable that other cases have been operated upon without it having been estimated necessary to mention them. Tribe (1963) in his series of I 50 autopsies and Pearce et al. (I964) on 30 autopsies do not mention peritonitis following appendicitis as a cause of death or associated morbidity.

The diagnosis can be already difficult in a normal subject and can be rendered even more so in a patient where visceral sensation is diminished, or absent, and where the main preoccupation, for the practitioner, is that of a urinary complication. An excellent synopsis on the cases of acute abdominal disease in paraplegic patients has been given by Wanebo et al. (1965).

Material. We have observed over a I-year span, from July I97I to 30 June I972, five patients in whom the diagnosis of appendicitis was most likely and was confirmed by operation, this on a total number of 77 patients with spinal cord lesions.

Case I. Gis, Alain, age 2I. Complete lesion below T6 by fracture of T6-7 in September 1966. Admitted to the Centre in 1968, he had previously presented numerous complications and interventions on the lower urinary tract including a cystostomy for a bladder stone. This young man had severe spasms of the lower limbs, not only, and predominantly, in flexion, but also in extension. He also had profuse sweating below the level of the lesion. On II July 197I his general status which had been poor in the previous 2 days became suddenly worse with a high oscillating temperature around $39^{\circ}-40^{\circ} \mathrm{C}$., pulse $100 / 1 \mathrm{IO}$, and heavily infected urine. The W.B.C. was 4500 per mm. ${ }^{3}$ (average W.B.C.: $4000-5000$ per mm. ${ }^{3}$ ). The suspicion of an 'acute abdomen' was put forward by the lack of appetite in the last days developing anorexia, no vomiting but nausea, and a very vague 'pain' in the right suprapubic region, pain which was only provoked, no sensation in that region having been recorded previously. Progressively, a considerable lowering of the spasticity was noted, and on palpation one could feel a very vague rise in local skin temperature in the lower right abdominal quadrant. His usual reflex perspiration in the abdominal region had also disappeared. His condition became rapidly worse and a MacBurney laparotomy was performed, showing a perforated appendix surrounded by a block of sclerosis yielding an abscess of $5000 \mathrm{ml}$. of pus in the Douglas pouch. Healing was partly unsuccessful and a repair of the surgical wound was performed 3 months later. A third intervention was necessary caused by a similar symptomatology, palpation revealing an unprecise mass in the right iliac fossa corresponding to a new Douglas abscess which was drained for I month. Since that period he is well, apart from a chronic urinary infection; no change in spasticity. 
Case 2. ABID, Abdallah, age 33. Incomplete tetraplegia below $\mathrm{C}_{7}$ by fracture of $\mathrm{C}_{7}, 8$ August 1970. Hyperspastic in the abdominal and lower limb muscles. Severe and frequent attacks of autonomic hyperreflexia. Sterile urine. Often constipated with pain over the whole colon. On 20 April 1972, he complained of a localised pain, unusual, in the right flank, suggesting a renal complication. The I.V.P. was normal a few days before. On the other hand, he was anorectic. No temperature: $36.5^{\circ} \mathrm{C}$. Pulse 80 . W.B.C.: 8500 per $\mathrm{mm}^{3}$ (average W.B.C.: $4000-6000$ per $\mathrm{mm}^{3}$.). Palpation of the right flank was painful over its whole surface. No pain localised in the right iliac fossa. No change in spasticity. Nevertheless one thought of an extra-renal complication causing appendicitis. MacBurney laparotomy: subacute appendicitis, subserous and retrocecal. Pathology subacute inflammation. Follow-up: delayed healing of the superficial skin wound due to spasticity.

Case 3. GeN, Alain, age 22. Complete paraplegia below $\mathrm{T}_{9}$ by fracture of $\mathrm{T}_{9}$ on I8 August 1968. Admitted in September 1970. Severe lower abdominal and lower limb spasticity. Chronic urinary infection after bladder and urethra surgical interventions. Frequent right-sided renal colics. On 17 January 1972 he complained of a well-localised pain in the right iliac fossa which he judged as different from a renal colic. $\mathrm{Bad}$ and rapid worsening of his general condition with nausea but no vomiting. No raised temperature: $37^{\circ} \mathrm{C}$. One noticed a considerable diminishing of the abdominal and lower limb spasticity in lying position but worsening in sitting position. W.B.C.: 5500 per mm. ${ }^{3}$ (average W.B.C.: 4500 per $\mathrm{mm}^{3}$ ). Pulse 80. Palpation evokes a typical pain in the MacBurney area. Operation: acute, non-perforated, suppurated appendicitis. Follow-up: no complications.

Case 4. ZIT, Ahmed, age 37. Complete cauda equina lesion below LI by fracture of $\mathrm{LI}$ on 23 March 197I. Admitted in January 1972. Permanent urinary infection. In February 1972, complained of pain in the right iliac fossa, radiating over the hip, descending along the anterior part of the thigh. Palpation of the right colon was painful. Temperature: $38^{\circ} \mathrm{C}$. Pulse: I06. W.B.C.: 15000 per mm. ${ }^{3}$ (average W.B.C.: 8000 per $\mathrm{mm}{ }^{3}$ ). Nausea. The diagnosis of appendicitis was made. The patient was operated 2 days later, thanks to 'personal persuasion' by case 2 ! Operation: acute appendicitis. Pathology: subacute appendicitis. Follow-up: no complications.

Case 5. Ha, Dominique, age 20. Incomplete motor and sensory tetraplegia below C6 by fracture of C6. Admitted I3 months after the accident. Usually sterile urine, but sometimes infected. On I6 June 1972 he complained of a pain in the right iliac fossa. He described his pain as identical to previous pains before the accident related to appendicitis attacks. No anorexia. No temperature: $36.5^{\circ} \mathrm{C}$. No change in his usual spasticity. W.B.C.: 7000 per $\mathrm{mm}^{3}{ }^{3}$ (average W.B.C.: 6000 per $\mathrm{mm} .^{3}$ ). Operation: subacute appendicitis. Pathology: chronic obliterating appendicitis in acute phase. Follow-up: no complications.

\section{DISCUSSION}

Diagnosis of appendicitis in the spinal man is difficult. It is of the greatest importance to know the patient's psychological and pathological reactions. The differential diagnosis is mainly that of a pathological process, either acute or chronic, of the urinary tract, and more seldom in the gall-bladder and gastric region, especially in very high lesions without splanchnic sensory afferences. Pain: deep visceral sensation is difficult to appreciate where it is, following a spinal cord lesion, diminished, changing or absent, variable from subject to subject according to the level. The usual spontaneous pain in tetraplegic or paraplegic 
patients is rather sharp of root type, or even phantom-like. Visceral pains corresponding to a somatic process are described as vague, sometimes oppressive, ill-defined and difficult to localise (Grossiord \& Pannier, I964; Rossier, I964; Burke, 1973). But, in normal practice abdominal pain can be very erratic and sometimes referred as in high spinal lesions, causing sometimes surprises at operation. Palpation sometimes may not evoke deep pain, not even a sensation. Loss of appetite or anorexia is frequent in paraplegics, but associated with a rapidly declining general condition can indicate that 'something' is happening. Nausea is also frequent and associated with renal or intestinal complications (mainly constipation). A rise in temperature is a common factor but not necessarily constant. Pulse variations are frequently associated with other syndromes. The examination of the patient can establish the diagnosis of appendicitis. Palpation can provoke a pain which, in low or incomplete lesions, is similar to that of a normal patient. The reference of the pain in high lesions is of great importance. The presence of a loaded, ascending, painful colon is most common. The appreciation of change of spasticity can be difficult in either way (Case I-Case 2) but the unilateral increase can be a useful sign. The classical defence is of value in low lesions where abdominal muscles are normally innervated. Rectal examination has been of no help in our five cases. The rise of local skin temperature can be of great help (Case I). Biological examinations are of poor value and the classical rise of the white blood count can be discussed in all our cases, knowing the average W.B.C. of the patients in the absence of a urinary tract infection. $X$-ray examination is of primordial value as to eliminate an urological process. Emergency intravenouspyelogram, now currently used even with patients with high temperature, must in any doubt be performed. The straight abdominal picture very often only shows a common colon stasis or aerocolon, not infrequent in paraplegic patients. We have not observed in any of our cases the classical X-ray pictures with multiple fluid levels on the right side or the presence of gas in the peritoneal cavity. An $\mathrm{X}$-ray - of the chest must be performed to eliminate any thoracic disorders, especially in high lesions.

\section{RÉSUMÉ}

Cinq cas d'appendicite subaigue ou aigue en un an, sur un total de 77 para- et tétraplégiques.

On discute les principaux aspects du diagnostic.

Les cas rapportés dans la littérature sont peu nombreux.

\section{ZUSAMMENFASSUNG}

Fünf Fälle, subakute oder akute Appendizitis, wurden, im Zeitraum von einem Jahr, bei ein Total von 77 Paraplegikern und Tetraplegikern, operiert.

Die Hauptaspekte der Diagnose werden erörtert.

Die in der Litteratur vorgebrachte Fälle sind nicht zahlreich.

\section{REFERENCES}

Bors, E. (I966). Proc. I5th Clinical Spinal Cord Injury Conference, p. I I5. Vet. Admin. U.S.A.

Burke, D. C. (1973). Int. F. Paraplegia, 10, 297.

Comarr, E. (I966). Proc. I5th Clinical Spinal Cord Injury Conference, p. iI6. Vet. Admin. U.S.A. 
GrEenField, J. (I949). Arch Surg. 59, I077-IO87.

Grossiord, A. \& PANNier, S. (1964). Proc. 4th International Congress of Physical Medicine, pp. 618-620.

Hoen, T. I. \& Cooper, I. S. (1948). Amer. Four. Surg. 75, 19-24.

Pearce, L. S., Perkins, H. E. \& Holliday, L. W. (1964). Proc. I3th Clinical Spinal Cord Injury Conference, pp. 88-92. Vet. Admin. U.S.A.

Ray, B. S. \& NeIll, C. L. (1947). Ann. Surg. 1 26, 709-724.

Rossier, A. B. (1964). Documenta Geigy, Acta Clinica, n ${ }^{\circ}$ 3, French Series, pp. 84-85.

TRIBE, C. R. (1963).. Int. F. Paraplegia, I, 19-46.

Wanebo, H. J., Webb, E. \& Combs, R. (1965). California Medicine, ro3, I93-I97. 